\title{
ARTICLE OPEN \\ Investigation of chloride-induced depassivation of iron in alkaline media by reactive force field molecular dynamics
}

\author{
Hossein DorMohammadi ${ }^{1}$, Qin Pang $\mathbb{D}^{2}$, Pratik Murkute ${ }^{3}$, Líney Árnadóttir ${ }^{4}$ and O. Burkan Isgor $\mathbb{D}^{5}$
}

The passivity of iron in alkaline media enables the use of carbon steel as reinforcement in concrete, which makes up the majority of modern infrastructure. However, chlorides, mainly from deicing chemicals or marine salts, can break down the iron passive film and cause active corrosion. Despite recent advances in nanoscale characterization of iron passivity, significant gaps exist in our understanding of the dynamic processes that lead to the chloride-induced breakdown of passive films. In this study, chlorideinduced depassivation of iron in $\mathrm{pH} 13.5 \mathrm{NaOH}$ solution is studied using reactive force field molecular dynamics. The depassivation process initiates by local acidification of the electrolyte near the film surface, followed by iron dissolution into the electrolyte, and iron vacancy formation in the passive film. Chlorides do not penetrate the passive film, but mainly act as a catalyst for the formation of iron vacancies, which diffuse toward the metal/oxide interface, suggesting a depassivation mechanism consistent with the pointdefect model.

npj Materials Degradation (2019)3:19; https://doi.org/10.1038/s41529-019-0081-6

\section{INTRODUCTION}

In highly alkaline electrolytes, typically those with $\mathrm{pH}$ greater than 12 , a protective passive film forms on iron that reduces metal dissolution rates from the substrate to the electrolyte to levels that can be considered practically insignificant. ${ }^{1,2}$ The passivity of iron in alkaline media allows the use of carbon steel in reinforced concrete $(\mathrm{pH}>13)$, which makes up the majority of the modern infrastructure. However, in the presence of deteriorative species, such as chlorides, iron (or carbon steel) can lose its passive film. The breakdown of the passive film (depassivation) can lead to higher rates of metal loss (active corrosion). ${ }^{3-6}$ Reinforcement corrosion in concrete because of exposure to chloride-containing deicing chemicals or marine salts is the most costly deterioration mechanism of reinforced concrete structures in the world. ${ }^{3-8}$ Therefore, the development of a fundamental understanding of chloride-induced depassivation is critical to mitigate corrosion issues in concrete infrastructure.

The passivity and chloride-induced depassivation of iron and carbon steel in the highly alkaline environments have been studied extensively using electrochemical techniques. ${ }^{9-13}$ These techniques provide valuable information about the average electrochemical behavior of relatively large metal surfaces, typically in centimeter-square scale or larger. However, passive films that form on carbon steel and iron in alkaline environments are typically $3-15-\mathrm{nm}$ thick $^{14-16}$; therefore, a deeper understanding of passivity can only be obtained through techniques that can characterize them at a nanometer scale.

In recent years, researchers have used nanoscale surface characterization techniques to study the structure of the passive films of iron that form in highly alkaline media and their chlorideinduced breakdown. ${ }^{14-20}$ These studies typically show that the passive films of iron in highly alkaline electrolytes consist of $\mathrm{Fe}^{2+}$-rich inner oxide layers and $\mathrm{Fe}^{3+}$-rich outer oxide layers. This multilayer film structure is in quantitative agreement with theoretical passivity models that suggest an inner barrier layer forms directly on the metal substrate, and the outer layer precipitating via the hydrolysis of cations ejected from the inner layer. ${ }^{14-16}$ Some of these studies also show that chlorides alter the passive film stoichiometry such that near the metal/film interface the ratio of $\mathrm{Fe}^{3+}$ to $\mathrm{Fe}^{2+}$ increases.

Even though these nanoscale surface characterization studies provide valuable information about passive films on carbon steel and iron in alkaline electrolytes, and their chloride-induced depassivation, they cannot explain the dynamic processes that lead to their formation or breakdown. Specifically, we still do not fully understand how chlorides initiate the depassivation process and how they are involved in passive film breakdown. Some of the depassivation models suggest that chlorides penetrate into the passive film through ion exchange processes or simple diffusion. ${ }^{21-23}$ However, other models hypothesize that chlorides only act as a catalyst, without penetrating into the film, to form iron vacancies that eventually diffuse to the metal/film interface to initiate the depassivation process. ${ }^{24,25}$ The debate between these different models is ongoing. Furthermore, electrochemical studies have shown that sufficient concentrations of chloride ions are needed at the film/electrolyte interface to initiate the depassivation process and this threshold concentration increases with the electrolyte $\mathrm{pH}^{12,26-29}$; however, it is not known exactly why this "critical chloride threshold" exists and why it is $\mathrm{pH}$ dependent. The concept of "induction time", ${ }^{30-32}$ which is the delay in the breakdown of the passive film at chloride concentrations beyond the critical thresholds is also not well understood. The absence of

\footnotetext{
'Oregon State University, School of Civil and Construction Engineering, Corvallis, OR, USA; ${ }^{2}$ Oregon State University, School of Chemical, Biological and Environmental Engineering, Corvallis, OR, USA; ${ }^{3}$ Oregon State University, Materials Science Program, School of Mechanical, Industrial and Manufacturing Engineering, Corvallis, OR, USA; ${ }^{4}$ Oregon State University, Materials Science Program, and School of Chemical, Biological and Environmental Engineering, Corvallis, OR, USA and ${ }^{5}$ Oregon State University, Materials Science Program, and School of Civil and Construction Engineering, Corvallis, OR, USA

Correspondence: O. Burkan Isgor (burkan.isgor@oregonstate.edu)
}

Received: 22 October 2018 Accepted: 2 April 2019

Published online: 23 April 2019 
well-supported theories/models for these fundamental questions impedes the development of new corrosion mitigation strategies, such as customized corrosion inhibitors and inexpensive corrosion-resistant steels.

Atomistic modeling techniques, such as reactive force field molecular dynamics (ReaxFF-MD) ${ }^{33-42}$ and density functional theory (DFT), ${ }^{43-48}$ have shown great potential to provide answers to such questions. In particular, ReaxFF-MD has emerged as a simulation framework to investigate reactive processes at spatial scales of $\mathrm{nm}^{2}$ that can be correlated to physical systems. In this paper, we use ReaxFF-MD to answer fundamental questions on chloride-induced depassivation of iron passive film in alkaline media. The simulations are supported with the electrochemical experiments and X-ray photoelectron spectroscopy (XPS) studies on iron that is exposed to conditions similar to those of the simulations. All studies were performed on pure (and in the case of ReaxFF-MD simulations, defect-free) iron, instead of carbon steel, in order to eliminate the effects of possible confounding variables that might hinder the answering of fundamental questions related to the passivation and chloride-induced depassivation processes in alkaline electrolytes. This assumption is justified by several electrochemical and thermodynamic studies that indicate that passivation and chloride-induced depassivation of carbon steel is mainly driven by the interaction of iron with the electrolyte. ${ }^{1,2}$ Carbon steel used for reinforced concrete applications typically has $0.2-0.4 \%$ of carbon by mass. Although carbon steel passivates slower than iron, ${ }^{49}$ and the critical chloride threshold of carbon steel is typically smaller than that of iron, ${ }^{26,30}$ the passivation and depassivation mechanisms of carbon steel and iron are considered to be similar.

The main objective of this research is to simulate the chlorideinduced depassivation process of pure iron in a highly alkaline environment $(0.316 \mathrm{M} \mathrm{NaOH}$ solution; $\mathrm{pH}=13.5)$ using ReaxFFMD. Although $\mathrm{NaOH}$ was chosen to match the $\mathrm{pH}$ of typical concrete pore solutions, the authors acknowledge that real concrete pore solutions are complex and contain several other ions, such as $\mathrm{Ca}^{+2}, \mathrm{~K}^{+},\left(\mathrm{SO}_{4}\right)^{-2}$ 9,16. These ions are known to affect the passivation process and the properties of the passive film, as also shown in an earlier work of one of the co-authors ${ }^{9,16}$; however, here we study a simplified electrolyte to gain fundamental understanding into the dynamic processes that lead to a chloride-induced depassivation process in a simple high $\mathrm{pH}$ electrolyte.

\section{RESULTS AND DISCUSSION}

Passive film

The initial passive film is created using ReaxFF-MD simulations starting with a Fe(110) structure $(24.61 \AA \times 20.40 \AA \times 22.87 \AA)$ containing $1080 \mathrm{Fe}$ atoms, in $0.316 \mathrm{M} \mathrm{NaOH}$ solution ( $\mathrm{pH} \sim 13.5$ ), containing $21 \mathrm{Na}$ and $\mathrm{OH}$ ions distributed evenly in equally spaced seven layers of 348 water molecules. Previous studies have shown that different surface orientations do not affect the oxidation behavior of iron significantly ${ }^{50-55}$; therefore, the $\mathrm{Fe}(110)$ is used here to represent a closely packed iron surface. Periodic boundary conditions were applied along the cross-sectional plane of the iron domain, while a fixed boundary condition was imposed along the longitudinal direction. For the periodic boundaries, particles interact across the boundary so that they can exit on one end of the simulation box and re-enter the other end, while for the fixed boundaries, particles do not interact across the boundary and do not move from one side of the simulation box to the other. A reflecting wall was applied at the end of the solution domain in order to confine the electrolyte and to avoid the interactions of the solution with the bottom of the periodic surface slab. Under open-circuit conditions, without any externally applied potential, passive film formation on iron in $\mathrm{NaOH}$ solution occur in minutes, which is not a feasible timescale to model using ReaxFF-MD. Faster passivation can be achieved by applying externally applied potential, which is a practice that is commonly used in electrochemical experiments. ${ }^{14,26,49}$ An external electric field was applied to accelerate chemical reactions and to overcome the challenges associated with long passivation time under opencircuit conditions. The simulations in this study were run with a $30 \mathrm{MeV} / \mathrm{cm}$ applied external electric field for $500 \mathrm{ps}$. Test simulations at higher potentials gave similar results. The electrical double layer (EDL) between the film surface and the electrolyte was modeled using the Stern model ${ }^{56}$ with a 3 - $\AA$-thick Helmholtz layer, ${ }^{39,57}$ and a diffuse layer where the ions are distributed in the electrolyte.

Figure 1a shows the passive film at the beginning of the ReaxFF$\mathrm{MD}$ simulations with the electrolyte containing chloride ions. After $500 \mathrm{ps}$ of simulations of $\mathrm{Fe}(110)$ in the chloride-free alkaline electrolyte, the film changed rather slowly, approximately at $10 \%$ of the initial rate. At this time the passive film was about $12-\AA$ thick and spanned six sheets of iron atoms (Fig. 1b). The iron atom charges ranged from 0.37 e to 0.97 e for the first (outermost) sheet, 0.28 e to $0.92 \mathrm{e}$ for the second sheet, $0.16 \mathrm{e}$ to $0.79 \mathrm{e}$ for the third sheet, $0.1 \mathrm{e}$ to 0.73 e for the fourth sheet, 0 to 0.55 e for the fifth sheet, and 0 to 0.26 e for the sixth sheet. This variability indicates that each depth contained various iron oxide structures; however, the overall charge of iron atoms decreases from the film/electrolyte interface to the metal/film interface. To further analyze the oxide structures, we divided the passive film into three layers (inner, middle, and outer layers), each containing two iron sheets. The $\mathrm{Fe}-\mathrm{O}$ pair distribution functions (PDF) of the layers are plotted in Fig. 1c, which also shows the dominant peak and transition points for the reference oxides (i.e., $\mathrm{FeO}, \mathrm{Fe}_{3} \mathrm{O}_{4}$, and $\mathrm{Fe}_{2} \mathrm{O}_{3}$ ) for comparison. ${ }^{58}$ The PDF of the outer layers shows a dominant peak at $1.69 \AA$ and a distinct transition at $2.17 \AA$, which match the reference signature for $\mathrm{Fe}_{2} \mathrm{O}_{3}$. The PDF of the middle layers has a dominant peak at $1.98 \AA$ and a slight transition point at $1.6 \AA$, which corresponds well with $\mathrm{Fe}_{3} \mathrm{O}_{4}$. Finally, the PDF of the inner layers has a dominant peak at $1.63 \AA$, which coincides with the dominant peak of $\mathrm{FeO}$. It should be noted that $\mathrm{FeO}$ is not a stable oxide on its own at room temperature, but it can exist as a transitional phase at the interface between the metal and the passive film, where the iron ions from the base metal is initially oxidized. ${ }^{20}$

These results are in agreement with the existing experimental data, which indicate that passive films of iron in highly alkaline electrolytes consist of $\mathrm{Fe}^{2+}$-rich inner oxide layers and $\mathrm{Fe}^{3+}$-rich outer oxide layers. ${ }^{14-20}$ Similar supporting evidence was obtained in our XPS investigation, which was performed on a passive film grown on $99.95 \%$ pure iron exposed to $\mathrm{pH} 13.5 \mathrm{NaOH}$ solution at open-circuit conditions. Figure $1 \mathrm{~d}$ shows how the ratio of $\mathrm{Fe}^{3+}$ to $\mathrm{Fe}^{2+}$ decreases from the film/electrolyte interface toward the metal/film interface: $\mathrm{Fe}_{2} \mathrm{O}_{3}$ fraction decreases, while $\mathrm{FeO}+\mathrm{Fe}_{3} \mathrm{O}_{4}$ fractions increase, toward the inner layers of the passive film. The XPS data, shown in Fig. 1d, were obtained from passive films that were grown in the passivating solution under open-circuit conditions for 2 weeks, they are, therefore, thicker and have a more mixed oxide composition than our simulated film. However, the overall comparison indicates that the passive film produced in the ReaxFF-MD simulations is a good starting structure to investigate the processes associated with chloride-induced depassivation.

Interaction of chlorides with the passive film

The electrolyte domain size was $24.46 \AA \times 21.46 \AA \times 21.59 \AA$ for the depassivation simulations, and three different $\mathrm{NaCl}$ concentrations were studied: $2 \mathrm{M}\left(293 \mathrm{H}_{2} \mathrm{O}, 14 \mathrm{NaCl}\right), 5 \mathrm{M}\left(232 \mathrm{H}_{2} \mathrm{O}, 34 \mathrm{NaCl}\right)$, and $10 \mathrm{M}\left(147 \mathrm{H}_{2} \mathrm{O}, 68 \mathrm{NaCl}\right)$. The chloride-induced depassivation simulations were done under smaller applied electric field $(15 \mathrm{MeV} / \mathrm{cm})$ to study the role of chlorides on the depassivation at near-open-circuit conditions. This electric field allowed us to 


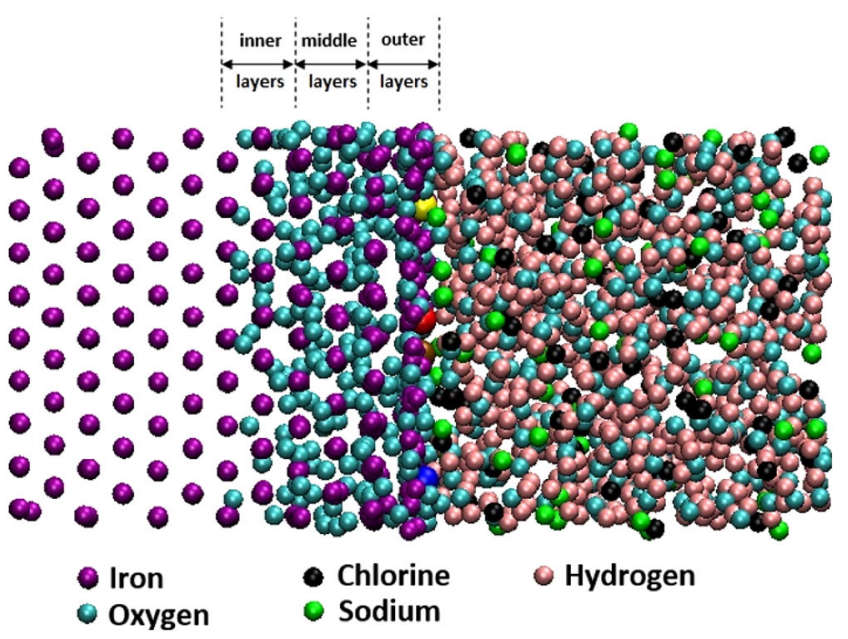

(a)

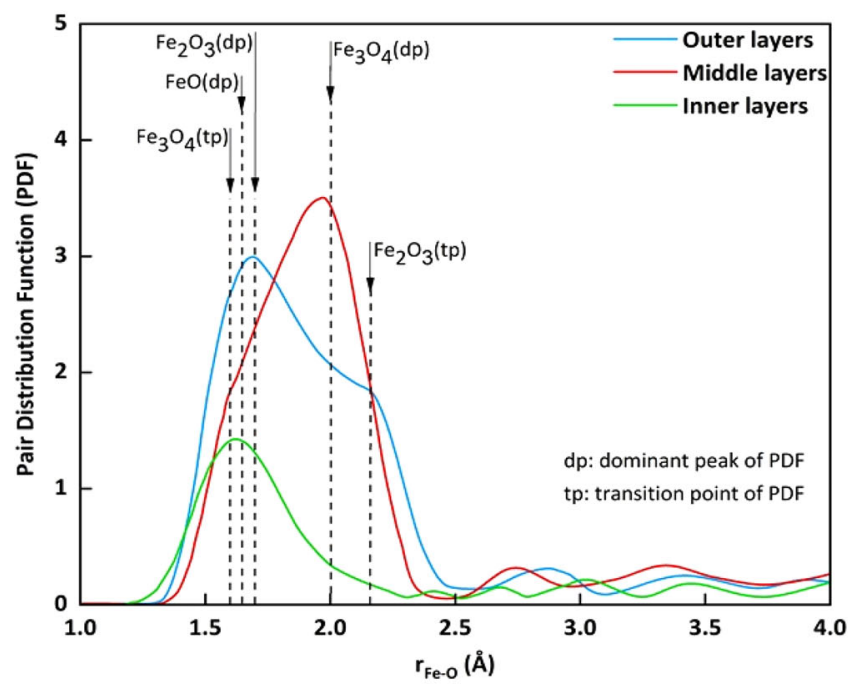

(c)

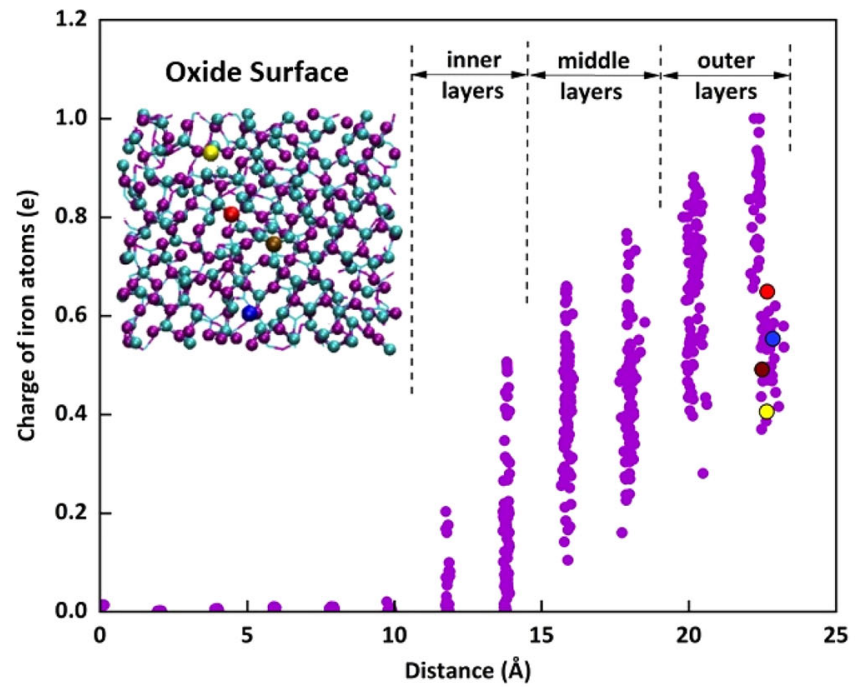

(b)

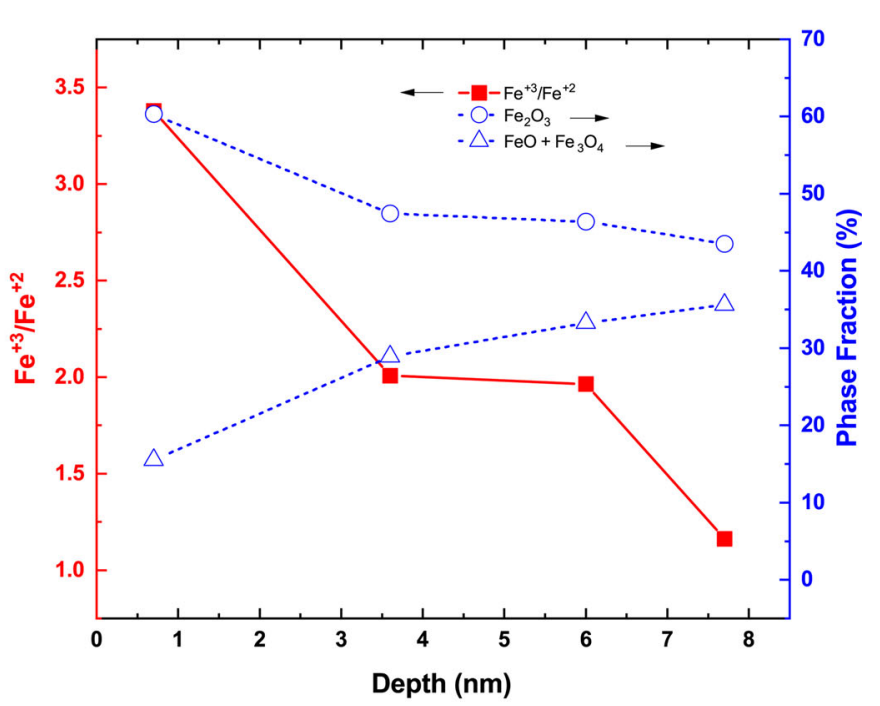

(d)

Fig. 1 a Starting configuration of the simulations showing the passive film, the electrolyte, and the chloride distribution. $\mathbf{b}$ The charge distribution of iron atoms in the passive film and the metal; the charges that are shown in this figure represent the charges of individual atoms. c Pair distribution function (PDF) of the inner, middle, and outer layers of the passive film. d Oxides composition in the passive film from the XPS analysis; iron metal and other minor oxides and satellite phases are not shown for clarity. Yellow, red, brown, and blue atoms in panels (a) and (b) are iron atoms that are discussed in detail in Fig. 2

observe depassivation during 2000 ps of simulations. Smaller electric fields also yielded similar initial results; however, advancing these simulations to later stages of depassivation would have required inhibitively long computational times. The electric field was kept smaller than the passivation simulations so that the role of chlorides on the depassivation can be investigated near opencircuit conditions.

Chloride-induced iron dissolution and corresponding iron vacancy formation in the outermost (first) layer of the passive film takes place in four stages. In the first and second stages, chlorides facilitate the consumption of hydroxide ions from the electrolyte by the surface iron to form $\mathrm{Fe}(\mathrm{OH})_{3}$ and $\mathrm{Fe}(\mathrm{OH})_{2} \mathrm{Cl}$, respectively, which remain stable on the surface during the simulations. These two processes cause local acidification, and eventual depletion of $\mathrm{OH}$, in the electrolyte adjacent to the surface. The following, third and fourth stages, lead to the dissolution of iron into the electrolyte in the form of $\mathrm{Fe}(\mathrm{OH}) \mathrm{Cl}_{2}$ and
$\mathrm{FeCl}_{3}$, respectively. These species further dissociate releasing the chlorides into the electrolyte; chloride, therefore, acts as a catalyst in the iron dissolution process. Snapshots from the simulations in Fig. 2 illustrate these four stages. We highlight four iron atoms as examples demonstrating the processes in each stage: yellow atom for stage 1, brown atom for stage 2, blue atom for stage 3 , and red atom for stage 4 . The same color code is used in Fig. $1 \mathrm{a}, \mathrm{b}$. The processes that are described in these stages occur at multiple locations at the film/electrolyte interface; the four atoms were selected for demonstration purposes.

Stage 1-Formation of $\mathrm{Fe}(\mathrm{OH})_{3}$

The chloride ions first interact with the iron atoms with low electrical charges in the first layer of the passive film. An example of such an iron atom (shown in yellow) and its interactions with three chloride ions are shown in Fig. 2a. The chloride ions form a 
(a)

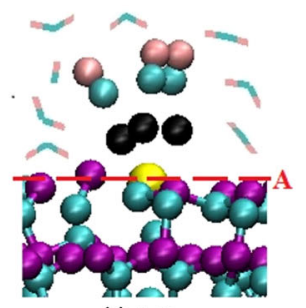

(i) $4.6 \mathrm{ps}$

(b)

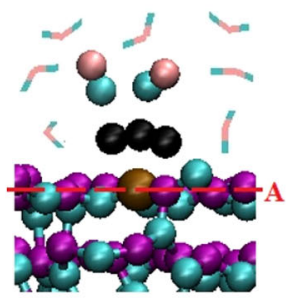

(i) $20.2 \mathrm{ps}$

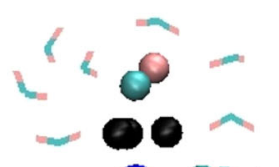

(c)

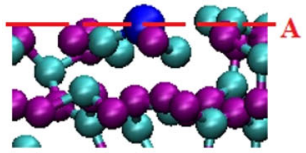

(i) $23.0 \mathrm{ps}$

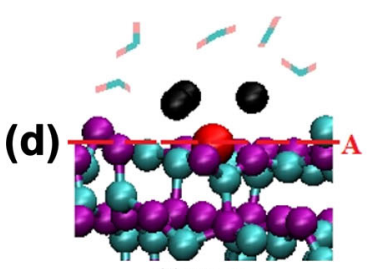

(i) $28.6 \mathrm{ps}$

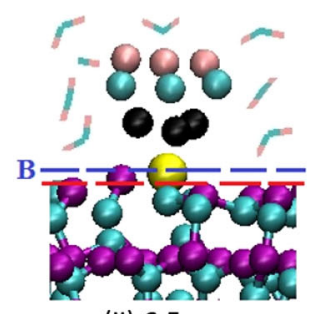

(ii) $6.5 \mathrm{ps}$

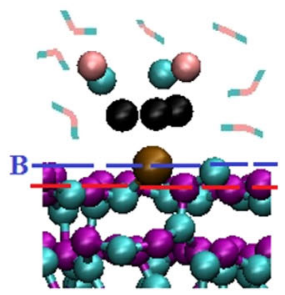

(ii) $22.3 \mathrm{ps}$

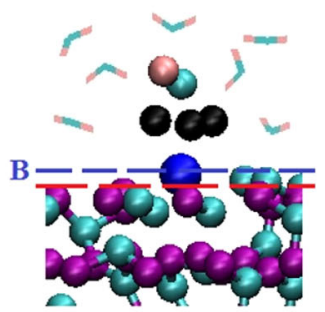

(ii) $25.2 \mathrm{ps}$

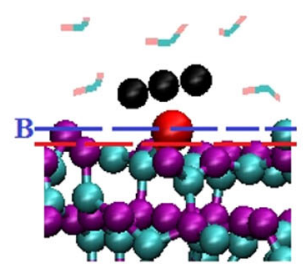

(ii) $31.0 \mathrm{ps}$

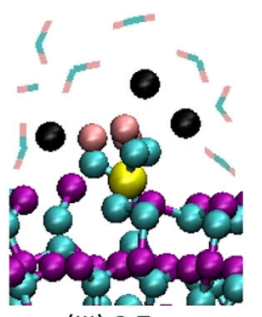

(iil) $8.7 \mathrm{ps}$

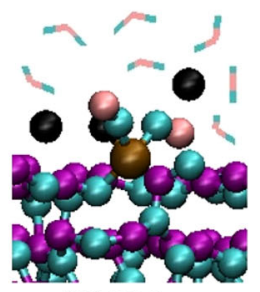

(iii) $24.3 \mathrm{ps}$

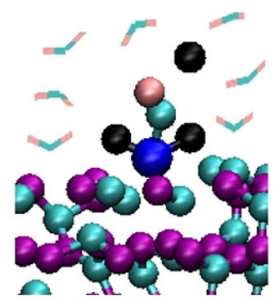

(iii) $27.1 \mathrm{ps}$

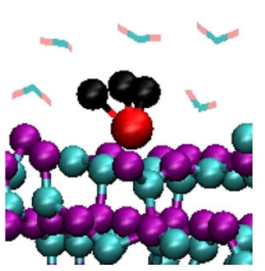

(iii) $32.7 \mathrm{ps}$

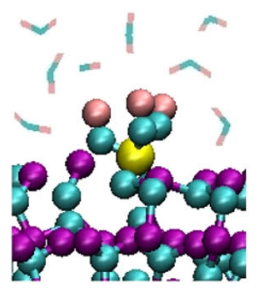

(iv) $14.0 \mathrm{ps}$

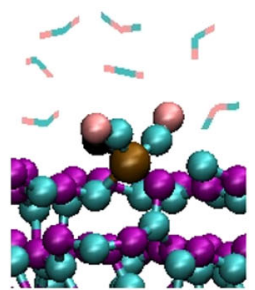

(iv) $29.0 \mathrm{ps}$

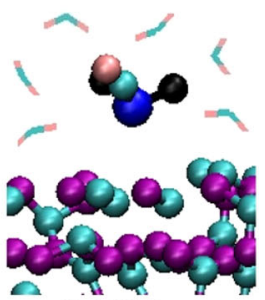

(iv) $32.0 \mathrm{ps}$

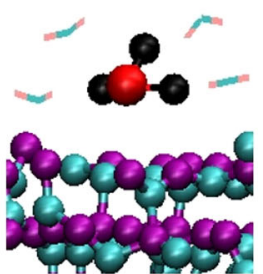

(iv) $38.0 \mathrm{ps}$

Fig. 2 Different stages of interactions of chloride and hydroxide with the iron oxide surface. All stages start with the formation of $\mathrm{FeCl}_{3}$ on the surface, but different stages lead to different products depending on the local OH concentration. a Formation of Fe(OH) 3 . b Formation of Fe $(\mathrm{OH})_{2} \mathrm{Cl}$. c Formation of $\mathrm{Fe}(\mathrm{OH}) \mathrm{Cl}_{2}$. d Formation of $\mathrm{FeCl}_{3}$. The locations of the yellow, brown, blue, and red iron atoms are shown in Fig. 1a, b. The time stamps of these example stages are included to illustrate the sequence of the stages

trigonal pyramidal configuration (i) and pull the iron atom out by $0.55 \AA$ (ii). The solution is highly alkaline, so the chlorides are replaced by hydroxide ions forming $\mathrm{Fe}(\mathrm{OH})_{3}$ (iii). $\mathrm{Fe}(\mathrm{OH})_{3}$ is stable on the surface and does not dissolve during the simulations (iv). This process results in the removal of three hydroxide ions from the electrolyte per iron atom, as shown in Fig. 3a. Multiple processes like this, lead to a local reduction of hydroxide ion concentration near the film/electrolyte interface.

\section{Stage 2-Formation of $\mathrm{Fe}(\mathrm{OH})_{2} \mathrm{Cl}$}

The initial step of stage 2 is similar to that of stage 1 with chloride ions interacting with iron atoms with low electrical charges in the first layer. Such an iron atom (shown in brown) and its interactions with three chloride ions are shown in Fig. $2 b$. As before, the chlorides pull the iron atom out of the surface by $0.54 \AA$ (i). Because of the formation of $\mathrm{Fe}(\mathrm{OH})_{3}$ as a result of the processes described in Stage 1, the local concentration of hydroxide decreased, and two chloride ions are replaced by hydroxide ions forming $\mathrm{Fe}(\mathrm{OH})_{2} \mathrm{Cl}$ (ii). The iron complex, $\mathrm{Fe}(\mathrm{OH})_{2} \mathrm{Cl}$, stays on the surface and does not dissolve in the solution on the timescale of our simulations, while the other two chloride ions return to the electrolyte (iii). This process results in the additional removal of two hydroxide ions from the electrolyte for each iron atom (iv). The repeated $\mathrm{Fe}(\mathrm{OH})_{3}$ and $\mathrm{Fe}(\mathrm{OH})_{2} \mathrm{Cl}$ formation leads to decreased concentration of hydroxides near the surface (Fig. 3a).

Stage 3-Formation of $\mathrm{Fe}(\mathrm{OH}) \mathrm{Cl}_{2}$

Figure $2 \mathrm{c}$ shows an iron atom (shown in blue) which is exposed to a locally acidified electrolyte due to repeated processes described in Stages 1 and 2. Three chloride ions interact with the iron atom forming a trigonal pyramidal configuration (i) and pull the iron atom out by $0.53 \AA$ (ii). Because of the low hydroxide ion concentration near the surface, only one chloride ion is replaced by hydroxide forming $\mathrm{Fe}(\mathrm{OH}) \mathrm{Cl}_{2}$ (iii). The chloride ion returns to the electrolyte, and the $\mathrm{Fe}(\mathrm{OH}) \mathrm{Cl}_{2}$ dissociates from the surface (iv). This is the first form of iron dissolution from the passive film. The $\mathrm{Fe}(\mathrm{OH}) \mathrm{Cl}_{2}$ is converted to $\mathrm{Fe}(\mathrm{OH})_{3}$ in the electrolyte, as has previously been shown in the literature, ${ }^{59}$ releasing of the chlorides and further reducing the local hydroxide concentration, 


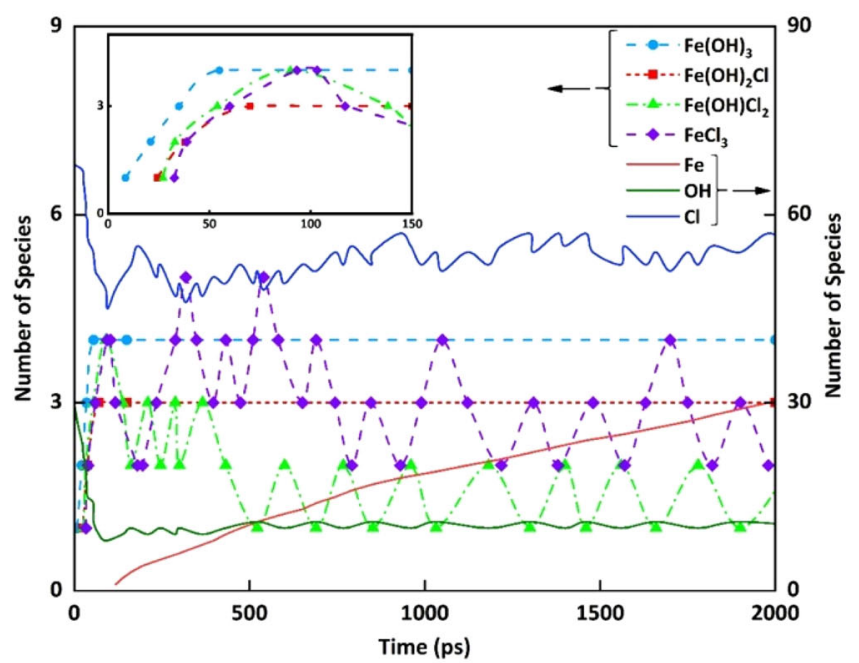

(a)

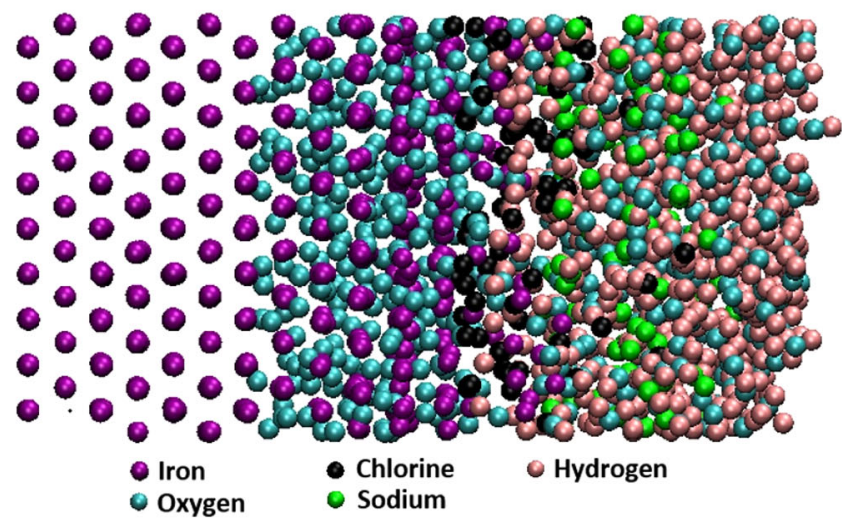

(b)

Fig. 3 a The evolution of the species on the film surface or in the electrolyte over the analysis time. $\mathbf{b}$ A configuration of the atoms at 2000 ps indicating the dissolution of the iron atoms from the film surface into the electrolyte. In (a), the calculations were done for the entire electrolyte domain, where electroneutrality is maintained. The number of Fe atoms (red line) is reported as the number of iron atoms that exist in the solid corrosion products that form in the electrolyte

causing further local acidification of the electrolyte near the film surface.

Stage 4-Formation of $\mathrm{FeCl}_{3}$

Figure $2 \mathrm{~d}$ shows an iron atom (shown in red) which is exposed to a locally acidified electrolyte due to repeated processes described in Stages 1-3. As before, three chloride ions form a trigonal pyramidal configuration above the iron (i), but here there are no hydroxide ions in this local zone to replace the chloride. The chlorides pull the iron atom out by $0.52 \AA$ (ii) forming a $\mathrm{FeCl}_{3}$ complex (iii) which dissolves into the electrolyte (iv). The $\mathrm{FeCl}_{3}$ is converted to $\mathrm{Fe}(\mathrm{OH})_{3}$ in the electrolyte releasing the chloride ions to the electrolyte where they can participate in another catalytic cycle of depassivation.

Figure $3 a$ illustrates the evolution of species on the film surface or in the entire electrolyte over the analysis period of $2000 \mathrm{ps}$. The four stages can be tracked for all species in this figure. One of the critical observations here is that the dissolution of iron from the passive film does not start until hydroxide ion concentration near the surface decreases, but the consumption of hydroxide is driven by the formation of $\mathrm{Fe}(\mathrm{OH})_{3}$ and $\mathrm{Fe}(\mathrm{OH})_{2} \mathrm{Cl}$ early on in the simulations. Note that these species remain stable on the surface during the entire 2000 ps of simulations ensuring that the electrolyte near the film surface remains locally acidified. The iron atoms that are exposed to locally acidified electrolyte dissociate from the passive film in the form of $\mathrm{Fe}(\mathrm{OH}) \mathrm{Cl}_{2}$ and $\mathrm{FeCl}_{3}$. The first $\mathrm{Fe}(\mathrm{OH}) \mathrm{Cl}_{2}$ dissociates from the passive film after the formation of $\mathrm{Fe}(\mathrm{OH})_{3}$ and $\mathrm{Fe}(\mathrm{OH})_{2} \mathrm{Cl}$ species. The first $\mathrm{FeCl}_{3}$ dissolves into the electrolyte soon after the formation of $\mathrm{Fe}(\mathrm{OH}) \mathrm{Cl}_{2}$. In this process, the chlorides play the role of a catalyst: being released back to the electrolyte, they then can return to the iron oxide surface, and detach another iron atom from the passive film repeating the process. The cumulative number of iron atoms in the electrolyte increases over time, while the number of chlorides oscillates around a constant number. The final configuration at 2000 ps, (Fig. $3 b)$, clearly shows the dissolved iron atoms in the electrolyte and the initiation of the breakdown of the passive film.

\section{Observations on chloride threshold}

The four-stage process for the initiation of the passive film breakdown also offers an explanation of the concept of the critical chloride threshold. It has been widely shown through electrochemical studies that chloride ion concentration in the electrolyte must exceed a certain critical threshold to initiate the breakdown of the passive film. ${ }^{12,26-29}$ As shown in our simulations, chlorides play the role of a catalyst and have two main functions in the depassivation process: first, they cause the local acidification of the electrolyte near the film/electrolyte interface through the processes described in Stages 1 and 2. Second, they cause the dissolution of iron atoms that are exposed to the $\mathrm{OH}$-depleted zones of the electrolyte, as depicted in Stages 3 and 4. Both roles require a sufficient number of chloride ions in the electrolyte. Simulations with $1 \mathrm{M}$ and $2 \mathrm{M} \mathrm{NaCl}$ in the electrolyte show neither local acidification, a step that is required to initiate the iron dissolution, nor the removal of iron atoms from the passive film surface suggesting that these chloride concentrations are too low to initiate the depassivation process of the film.

On the other hand, simulations in $5 \mathrm{M} \mathrm{NaCl}$ solution have shown a similar behavior to those observed in $10 \mathrm{M} \mathrm{NaCl}$ solution, eventually leading to iron dissolution into the electrolyte and iron vacancy formation. Our electrochemical tests on pure iron, passivated in $\mathrm{pH} 13.5 \mathrm{NaOH}$ solution, showed that the specimens lost their passivity when the chloride concentration in the solution was between 2 and $2.5 \mathrm{M}$. Figure $4 \mathrm{a}, \mathrm{b}$, respectively show, the electrochemical impedance spectroscopy (EIS) bode plots for impedance and phase angle for pure iron exposed to $13.5 \mathrm{pH}$ $\mathrm{NaOH}$ aqueous solution at full passivation (2 weeks) and at incremental chloride additions. At $2.5 \mathrm{M}$ chloride addition, the low-frequency impendence, which is the sum of the charge resistance of the film $\left(R_{c t}\right)$ and the solution resistance $\left(R_{s}\right)$, show a sharp decrease. This decrease is accompanied by an increase in the phase angle from $-90^{\circ}$ to about $-70^{\circ}$ in the mid- to lowfrequency range, which indicates a deviation from ideal capacitive behavior.

This critical chloride threshold is in agreement with similar electrochemical tests results from the literature for pure iron with pristine surface ${ }^{30}$ and in qualitative agreement with our simulations. It should be noted that critical chloride threshold for carbon steel in similar electrolytes is typically lower than the reported values for pure iron, which indicates that the crystal structure, impurities, and defects affect the critical chloride content. Our results also support a well-documented electrochemical observation that critical chloride thresholds are higher in electrolytes with higher $\mathrm{pH}^{30}$ The effect of $\mathrm{pH}$ on the critical chloride threshold can be explained with the need for local acidification of the electrolyte 


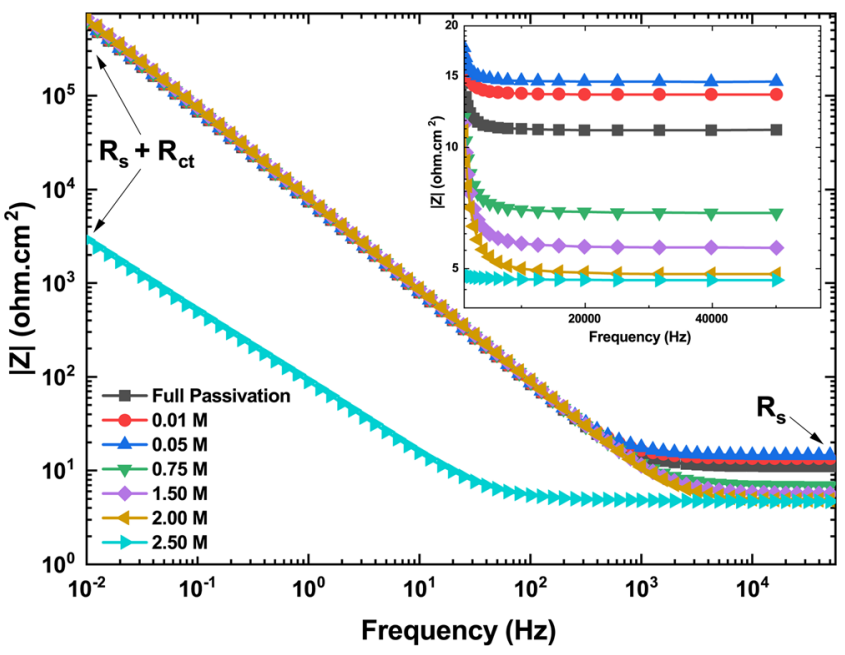

(a)

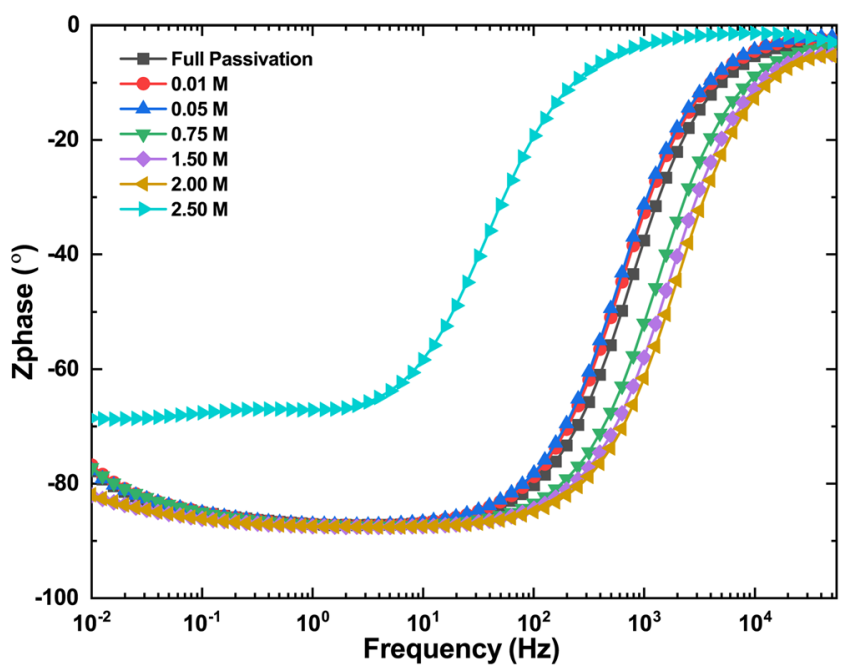

(b)

Fig. 4 Bode plots from EIS measurements of the pure iron sample exposed to $13.5 \mathrm{pH} \mathrm{NaOH}$ aqueous solution at full passivation and with increasing chloride concentrations: (a) impedance, (b) phase angle

near the film surface, where at higher $\mathrm{pH}$ more chloride ions are needed to acidify the electrolyte.

\section{Depassivation mechanism}

Another point of debate in the literature has been the actual mechanism of breakdown of the passive film. Some of the proposed mechanisms for passive film breakdown hypothesize the adsorption and ingress of chlorides through the outer layers of the oxides into the passive film. In these models, the penetrated chlorides cause the dissolution of the passive film from within and/or increase the iron oxidation rate of the metal substrate such that the passive film breaks down due to excessive generation of oxides. Among these models, the ion exchange model ${ }^{21}$ suggests a penetration of chloride ions into the oxide film through an ion exchange process (e.g., $\mathrm{Cl}^{-}$for lattice $\mathrm{O}^{2-}$ ). On the other hand, the pore models $\mathrm{s}^{22,23}$ are based on the fact that typical oxide layers contain flaws and are porous in nature; therefore, chlorides can pass through the pores and reach metal/film interface to disturb passivity. Our simulations do not support depassivation models that are based on the ingress of chlorides into the passive film. In fact, in all our simulations, chlorides remained either adsorbed on the surface of the passive film or in the electrolyte and caused the generation of iron vacancies within the first iron oxide layer.

Figure 5, which illustrates several time steps in a single plot, tracks the movement of the iron and oxygen vacancies as well as the iron and oxygen atoms within the passive film. The process starts with the dissolution of the iron atoms with a low electrical charge (typically less than $0.5 \mathrm{e}$ ) in the first (outermost) layer of the passive film into the electrolyte. The dissolved iron atoms, shown in blue, typically have a charge of $1.0 \mathrm{e}$. The vacancies that are left from the dissolved iron atoms are filled with lower charged iron atoms, shown in brown, from the second layer of the passive film. In later stages, these iron atoms are dissolved into the electrolyte as well as indicated by the brown atoms with a charge of $1.0 \mathrm{e}$ in the electrolyte. The vacancies left in the second layer are filled with the lower charged iron atoms from the third layer (shown in green). These chain processes lead to the movement of iron atoms from deeper layers of the passive film into the electrolyte, while the iron vacancies move in the opposite direction, eventually, reaching the metal/film interface. The movements of iron atoms and their vacancies are accompanied by the movement of oxygen atoms toward the metal/film interface, where additional iron atoms are oxidized as more oxygen becomes available. Meanwhile, oxygen vacancies move toward the film/electrolyte interface.

These processes support the depassivation hypothesis that is described by the point-defect model, ${ }^{24,25}$ which states that localized detachment of the oxide film occurs when a sufficient number of iron vacancies reaches the metal/film interface. At these detached sites, iron oxidation (i.e., oxide film growth or oxygen vacancy formation) stops. Simultaneously, the film becomes thinner due to the continued dissolution of iron from the film/electrolyte interface. This process continues until the passive film breaks down, either due to complete dissolution or mechanical rupture due to induced stress.

Although our simulations do not extend to the full breakdown of the passive film due to long timescales required for such simulations, we clearly show iron vacancy formation and diffusion, and the formation of point defects at the metal/film interface. Our XPS and EIS results also confirm a decrease in the charge transfer resistance and thickness of the passive film in $\mathrm{NaCl}$ solution. The charge transfer resistance decreased from $3.174 \times 10^{6} \mathrm{ohm} . \mathrm{cm}^{2}$ at full passivation to $3.220 \times 10^{4} \mathrm{ohm} . \mathrm{cm}^{2}$ in the same solution as presented in Fig. 6a. The film thickness decreased from $5.27 \mathrm{~nm}$ at full passivation to $4.17 \mathrm{~nm}$ in $2.5 \mathrm{M} \mathrm{NaCl}$ solution as shown in Fig. 6b. Furthermore, the low-frequency impedance (e.g., at $0.01 \mathrm{~Hz}$ ) decreases by two orders of magnitude going from full passivation $\left(5.89 \times 10^{5} \mathrm{ohm} . \mathrm{cm}^{2}\right)$ to depassivation at the same conditions $\left(2,896 \mathrm{ohm} . \mathrm{cm}^{2}\right)$ as shown in Fig. 4a.

The ReaxFF-MD simulations also provide evidence for another electrochemical observation that is widely reported in the literature: the induction period. ${ }^{30-32}$ The induction period refers to the period between the accumulation of adequate concentration of chloride ions in the electrolyte and the actual breakdown of the passive film. Several researchers have reported induction periods using electrochemical methods. ${ }^{30-32}$ Our simulations show that the passive film remains intact during iron dissolution from the surface of the film, as well as during iron vacancy formation and diffusion.

Figure 7a illustrates the changes in the Fe-O PDF of the outer, middle, and inner layers of the passive film, at 2000 ps, after $10 \mathrm{M}$ $\mathrm{NaCl}$ exposure. The solid lines represent the initial passive state (at $0 \mathrm{ps})$, and the dashed lines indicate the state after chloride exposure for $2000 \mathrm{ps}$. The reduction of the intensity of the PDFs indicates the thinning of the passive film, as predicted by the point-defect model. We also observe clear shifts in the dominant peak locations of the inner and middle layers, which were 


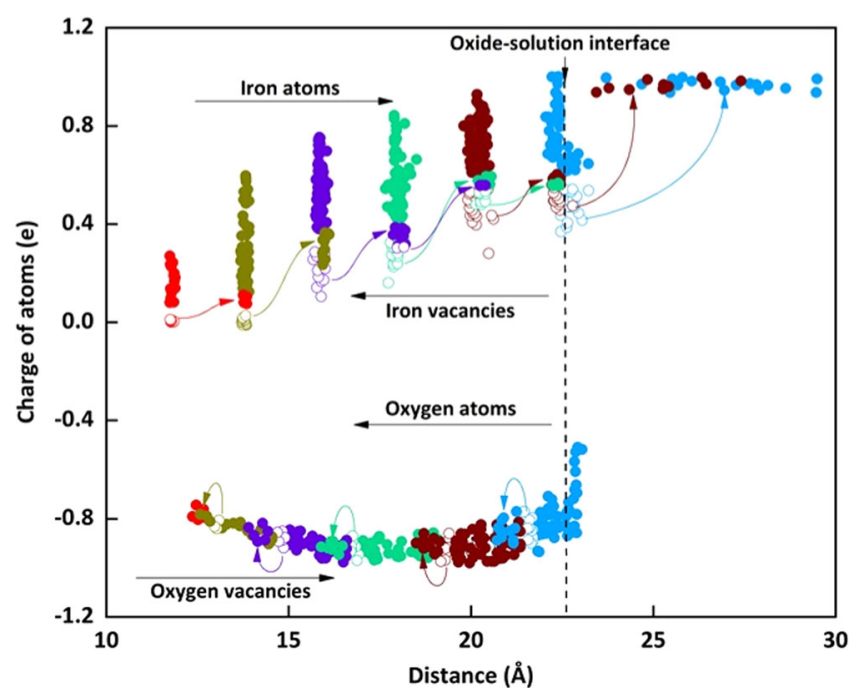

Fig. 5 Changes in charge distribution of the iron and oxygen atoms as a result of iron dissolution, indicating iron vacancy formation. The solid dots are the atoms, and the circles represent the corresponding vacancies. The figure covers different time steps during simulations. In the first layer, the iron atoms with the lowest charge are dissolved into the electrolyte (blue), some of the iron vacancies formed in the first layer are filled by low-charge iron atoms from the second layer (burgundy). The vacancies in the second layer are filled by iron with a low charge from the third layer (green) leading to net diffusion of iron vacancies into the oxide layer while the oxygen vacancies diffuse toward the surface

originally identified as $\mathrm{FeO}$ and $\mathrm{Fe}_{3} \mathrm{O}_{4}$ in the passive state. The PDF of the middle layer, at 2000 ps, showed a shift in the main peak from $1.98 \AA$ to $1.75 \AA$ and a formation of a transition point around $2.17 \AA$. This change indicates that $\mathrm{Fe}_{3} \mathrm{O}_{4}$ of the middle layer was transformed to a $\mathrm{Fe}_{2} \mathrm{O}_{3}$ structure. For the inner layer, the dominant peak is shifted from $1.63 \AA$ to $1.68 \AA$, and a slight transition point was observed at about $2.14 \AA$. This is an indication that the $\mathrm{FeO}$ structure transforms to $\mathrm{Fe}^{3+}$ oxides over time. The PDF pattern of the outer layer after chloride exposure was very similar to the passive state, indicating that oxide structure remained in the form of $\mathrm{Fe}_{2} \mathrm{O}_{3}$. Overall, the chlorides increase the $\mathrm{Fe}^{3+} / \mathrm{Fe}^{2+}$ ratio of the passive film, and this increase is more evident in the inner and middle layers of the film. Our XPS results also confirm this conclusion; Fig. $7 \mathrm{~b}$ shows how the $\mathrm{Fe}^{3+} / \mathrm{Fe}^{2+}$ ratio increases significantly after $2.5 \mathrm{M}$ chloride addition to the electrolyte. This concentration has been shown to be higher than the critical chloride threshold by our electrochemical tests, but the $\mathrm{Fe}^{3+} / \mathrm{Fe}^{2+}$ ratio does not change significantly between a passive state (no chloride) and $1 \mathrm{M}$ chloride addition (which is below the critical chloride threshold).

In order to provide supporting evidence for the depassivation mechanism suggested by the atomistic simulations, we used the XPS data to study the presence of chlorine in the passive film. Since the point-defect model is based on the process that chlorides do not penetrate into the film, the absence of chlorine in the film would provide additional supporting evidence for this depassivation mechanism. However, ex situ studies are known to be challenging to investigate ionic ingress into films. ${ }^{14-16}$ As described in the Methods section, XPS samples were exposed to $\mathrm{NaCl}$ solution before they were dried and prepared for the XPS scans. During the drying process, microscale $\mathrm{NaCl}$ crystals precipitated on the sample surface. We did not clean these precipitates using harsh procedures so that the oxide film of interest would not be affected. XPS is a highly surface-sensitive method that might indicate the presence of $\mathrm{NaCl}$ precipitations as subsurface chlorine. One approach to eliminate this artifact would

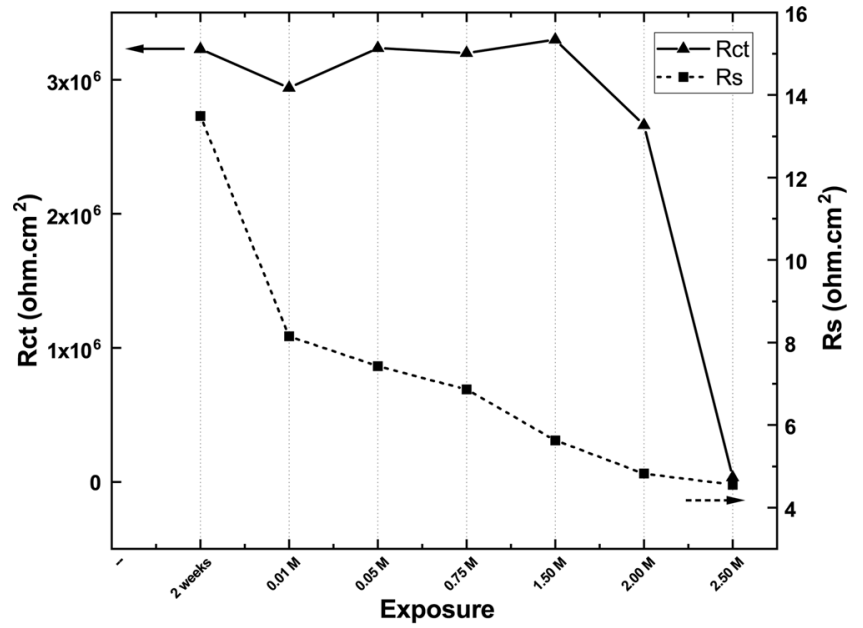

(a)

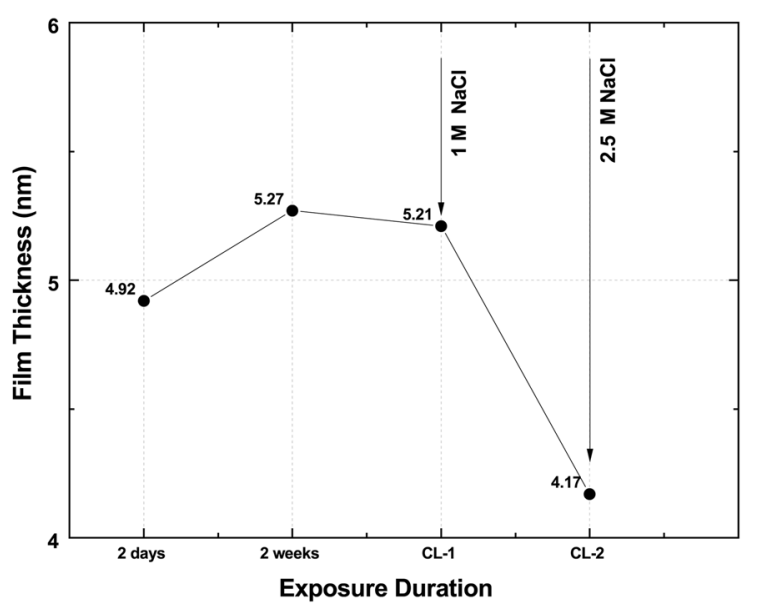

(b)

Fig. 6 a Solution resistance $\left(R_{s}\right)$ and charge transfer resistance of the film $\left(R_{c t}\right)$ with increasing chloride concentration. b Oxide film thickness at full passivation ( 2 weeks exposure), at $1 \mathrm{M} \mathrm{NaCl}$ (below critical chloride threshold), and at $2.5 \mathrm{M} \mathrm{NaCl}$ (above critical chloride threshold)

be to sputter the surface to determine if there is a sharp drop in the chlorine concentration, but sputtering might affect the oxide. Modeling approaches to estimate film thickness and expected drop in signal with depth, based on inelastic mean free paths of the electrons are also challenging due to the complexity of the system, namely, roughness and lack of film homogeneity.

With this caveat, we tried to interpret the chlorine profile in the passive film as shown in Fig. 7b. The absence of chloride signature throughout the passive film when it is exposed to $1 \mathrm{M} \mathrm{NaCl}$ solution indicates that, at the levels below the critical chloride threshold, $\mathrm{Fe}(\mathrm{OH})_{2} \mathrm{Cl}$ does not form and chlorides do not penetrate into the passive film. In addition, we also observed that at these low concentrations, $\mathrm{NaCl}$ crystals did not form extensively on the metal surface upon drying. Therefore, the absence of chlorine in the passive film is a piece of strong supporting evidence that chloride did not penetrate into the passive film. For the samples that were exposed to $2.5 \mathrm{M} \mathrm{NaCl}$ solution, we observed the formation of $\mathrm{NaCl}$ crystals on the sample surface. As shown in Fig. 7b, for these samples, the chlorine profile showed signs of subsurface presence; however, we attributed this to the presence of $\mathrm{Fe}(\mathrm{OH})_{2} \mathrm{Cl}$ on the first layer of the passive film, as indicated by our simulations, and the presence of 
the $\mathrm{NaCl}$ crystals on the sample surface. We interpreted these results as preliminary evidence that chlorides did not penetrate into the passive film, but can exist in the first layer of the passive film as suggested in the first two stages of the iron dissolution process. A piece of conclusive experimental evidence is still needed to confirm our interpretation. This experimental evidence can come from in situ ambient pressure XPS techniques, which are not currently mature enough to carry out these experiments in solution without the need to dry the samples during sample preparation.

In this paper, we used ReaxFF-MD to answer fundamental questions regarding the mechanism of chloride-induced depassivation of iron in alkaline media. The simulations were supported by electrochemical tests and XPS studies. The passive film was created using ReaxFF-MD simulations in $\mathrm{pH} 13.5 \mathrm{NaOH}$ solution and contained multiple oxide layers. The outer, middle, and inner layers of the passive film had oxides structures similar to those for $\mathrm{Fe}_{2} \mathrm{O}_{3}, \mathrm{Fe}_{3} \mathrm{O}_{4}$, and $\mathrm{FeO}$, respectively.

The breakdown of the passive film by chlorides initiates with iron dissolution from the first layer of the passive film into the electrolyte. Iron dissolution and corresponding iron vacancy formation in the first layer of the passive film take place in four stages. In the first and second stages, chlorides facilitate the consumption of hydroxide ions in the electrolyte by the iron surface to form stable $\mathrm{Fe}(\mathrm{OH})_{3}$ and $\mathrm{Fe}(\mathrm{OH})_{2} \mathrm{Cl}$ surface species, respectively. These two processes cause local acidification, and eventual local depletion of $\mathrm{OH}$, in the electrolyte adjacent to the film surface. The following third and fourth stages lead to the dissolution of iron into the electrolyte in the form of $\mathrm{Fe}(\mathrm{OH}) \mathrm{Cl}_{2}$ and $\mathrm{FeCl}_{3}$, respectively. After the dissolution of the iron, the chloride ions are returned to the electrolyte where they catalyze further depassivation.

This four-stage process for the initiation of the passive film breakdown also helps explain the concept of a critical chloride threshold where a sufficient amount of chloride ions is necessary to cause the local acidification of the electrolyte and subsequent iron dissociation. When chloride concentration in the electrolyte is below a critical threshold, these processes do not proceed, and the passive film remains stable. The same reasoning also explains the well-documented electrochemical observation that critical chloride thresholds increase with higher $\mathrm{pH}$. Higher $\mathrm{pH}$ implies a higher concentration of hydroxides close to the surface, and hence, a higher concentration of chloride ions is needed for localized acidification of the electrolyte.

Our simulations do not support depassivation models that require ingress of chlorides into the passive film. In fact, in all our simulations, chlorides remained either adsorbed on the surface of the passive film or remained in the electrolyte and catalyzed the generation of iron vacancies within the first iron oxide layer. The ReaxFF-MD simulations support the depassivation hypothesis that is described by the point-defect model, which states that when a sufficient number of iron vacancies reach the metal/film interface, they may cause localized detachment of the oxide film. At these detached sites, iron oxidation stops, and the film begins to thin due to the continued dissolution of iron from the film/electrolyte interface. Although our simulations do not extend to a full breakdown of the passive film due to the long timescales required for such simulations, we clearly show iron vacancy formation and diffusion in the passive film, as well as the formation of point defects at the metal/film interface. Our XPS and EIS results also confirm the decrease in the thickness of the passive film. Both the simulations and XPS results indicate that chlorides do not penetrate into the passive film, but can exist in the first layer of the passive film as demonstrated in the first two stages of the depassivation process.

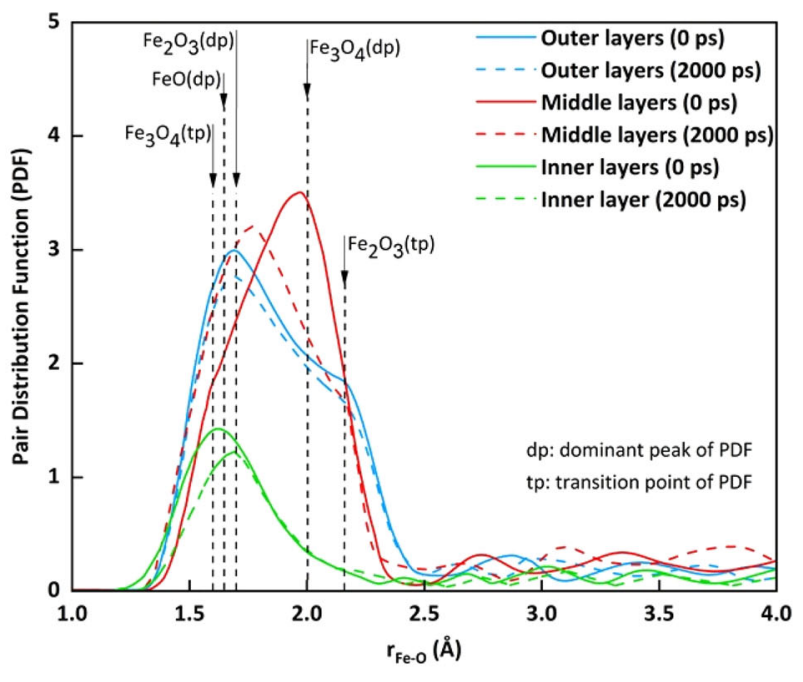

(a)

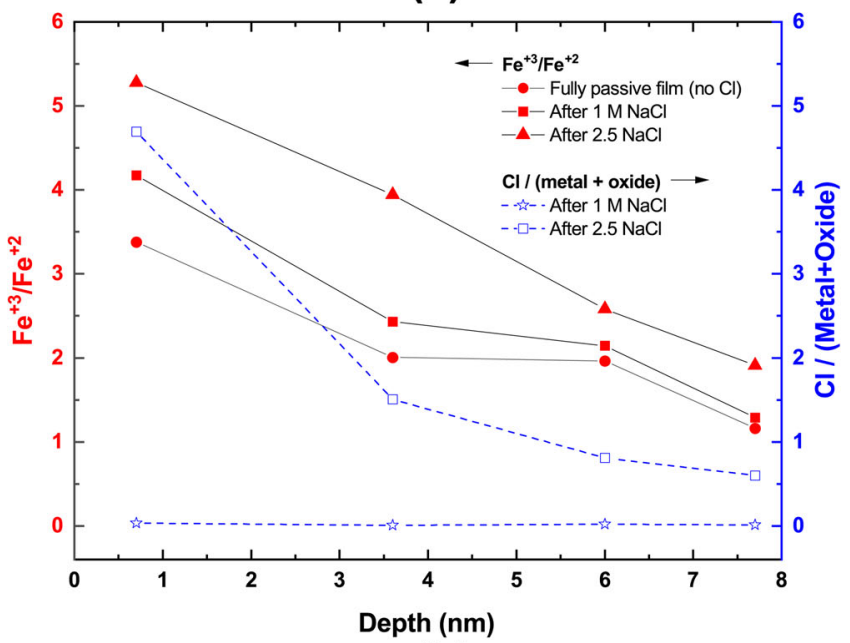

(b)

Fig. 7 a Simulated pair distribution function (PDF) of the inner, middle, and outer layers of the passive film before ( 0 ps) and after $(2000 \mathrm{ps})$ chloride exposure. b XPS analysis of $\mathrm{Fe}^{3+} / \mathrm{Fe}^{2+}$ ratios and $\mathrm{Cl} /(\mathrm{Fe}+\mathrm{O})$ ratios at different depths in the passive film after chloride exposure at different concentrations

\section{METHODS}

\section{ReaxFF-MD simulations}

ReaxFF-MD simulations were performed using the Large-scale Atomistic/ Molecular Massively Parallel Simulator (LAMMPS) framework ${ }^{60}$ and the Extreme Science and Engineering Discovery Environment (XSEDE). ${ }^{61}$ The ReaxFF framework was based on the interatomic potential theory developed by van Duin et al. ${ }^{62}$ The detailed explanation of the framework is provided by van Duin et al. ${ }^{33,36,40,42,58,63,64}$ The specific ReaxFF parameters for iron and other interacting species (e.g., $\mathrm{Na}, \mathrm{O}, \mathrm{H}$, and $\mathrm{Cl}$ ) were obtained from the works of Aryanpour et al., ${ }^{34}$ Rahaman et al., ${ }^{65}$ and Psofogiannakis et al., ${ }^{64}$ who developed parameters to model ironoxyhydroxide systems, chloride-water and copper chloride-water systems, and hydration of zeolite, respectively. We validated these parameters (that are required for determining the bond order, bond energy, valence angle energy, torsional angle energy, and van der Waals energy) by comparing ReaxFF-MD simulations of the surface formation energy and water adsorption energy on the $\mathrm{Fe}(110)$ surface with DFT calculations. ${ }^{50}$

All ReaxFF-MD simulations were performed at room temperature $(300 \mathrm{~K})$ under standard atmospheric pressure (1 atm). The initial distance between molecules and ions in the electrolyte and the dimensions of the vacuum slab were determined based on the density of the solution at $300 \mathrm{~K}$ and 
$1 \mathrm{~atm}$. Nose-Hoover thermostat ${ }^{66,67}$ was employed to maintain the prescribed system temperature for canonical (NVT) ensemble. The Velocity-Verlet time stepping scheme ${ }^{68}$ was used with an integration time step of $0.1 \mathrm{fs}$. The Maxwell-Boltzmann distribution ${ }^{69,70}$ was chosen to set the initial velocities, and an energy minimization was performed before the simulation. The center of the mass of the system was fixed during the simulation to eliminate any translational movements.

Specimen preparation for XPS scans and electrochemical tests

The electrochemical tests and XPS scans were performed on circular disks $(\varnothing=15 \mathrm{~mm}$, thickness $=2 \mathrm{~mm})$ of $99.95 \%$ pure iron. Both sides of the disks were polished with 2000-grade silicon carbide paper followed by cloth polishing with $0.3 \mu \mathrm{m}$ and $0.05 \mu \mathrm{m}$ alumina suspension in anhydrous isopropyl alcohol (water content: $<0.05 \%$ weight). Anhydrous isopropyl alcohol suspension was used in place of water suspension to minimize surface oxidation during the polishing process. After surface preparation, iron specimens were cleaned ultrasonically, dried, and stored in an anaerobic nitrogen chamber to minimize surface oxidation.

Three specimens were placed in three-electrode electrochemical cells containing the passivating solution for electrochemical testing. Additional six specimens were placed in a container with the passivating solution for XPS testing. A $0.316 \mathrm{M} \mathrm{NaOH}$ solution $(\mathrm{pH}=13.5)$ prepared with ASTM Type II water ${ }^{71}$ was used as the passivating solution for both XPS and electrochemical test specimens. The XPS specimens were exposed to passivating $\mathrm{NaOH}$ solution in an anaerobic nitrogen chamber to minimize the carbonation of the high $\mathrm{pH}$ solution with the atmospheric $\mathrm{CO}_{2}$. The $\mathrm{pH}$ of the solution was continually monitored and was maintained between 13.4 and 13.5 for the entire duration of the passivation period.

Three specimens that were separately tested in the electrochemical cells were exposed to the passivating solution for 2 weeks. Two XPS specimens were taken out of the solution at 2-week exposure period. The 2-week-long passivation time was chosen to guarantee full passivation under opencircuit conditions, as confirmed by the electrochemical tests. After full passivation, chloride concentration of the electrolyte in the electrochemical cells and in the container with the XPS specimens was increased incrementally using $99.99 \%$ analytical grade $\mathrm{NaCl}$ addition. In electrochemical tests, the chloride increments ranged from $0.01 \mathrm{M}$ to $2.5 \mathrm{M} \mathrm{NaCl}$ However, based on the electrochemical test results, the chloride increments for XPS specimens were $1 \mathrm{M}$ and $2.5 \mathrm{M} \mathrm{NaCl}$, so that they cover ranges both below, and beyond the critical chloride threshold. Two specimens were removed from the solution after $24 \mathrm{~h}$ of each chloride increment, for XPS tests. All XPS specimens that were removed from exposure solutions were rinsed with anhydrous isopropyl alcohol, dried in nitrogen chamber, and kept in a nitrogen-filled desiccator until analysis.

\section{Electrochemical tests}

Repeated cycles of open-circuit potential (OCP) and electrochemical impedance spectroscopy (EIS) measurements were performed on the specimens placed in the three-electrode cells during passivation period and the following period during which chlorides are incrementally added. All the electrochemical tests were performed using a Gamry 3000 Reference potentiostat and frequency response analyzer. Graphite counter electrode and a saturated calomel reference electrode (SCE) were used. For 2 weeks of exposure, in each cycle, OCP was monitored for $2 \mathrm{~h}$, followed by an EIS scan. The frequency scan range for EIS measurements was $50000-0.001 \mathrm{~Hz}$ during the passivation period and $50000-0.01 \mathrm{~Hz}$ during chloride additions, 10 points per decade. The amplitude of the AC voltage was $5 \mathrm{mV}$ rms.

\section{XPS scans}

All the specimens were analyzed in angle-resolved XPS within a few hours of taking them out of the solution. Specimens were mounted on the specimen holder and subsequently transferred directly to the forechamber of the XPS spectrometer and purged with dry nitrogen gas. This chamber was evacuated to $\sim 10^{-6}$ Torr before the specimens were transferred to the analytical chamber for examination. The analytical chamber was an ultra-high vacuum (UHV) chamber with vacuum of $10^{-9}$ Torr. The specimens were analyzed using the Physical Electronics PHI 5600 ESCA system equipped with a monochromatic Al X-ray source (X-ray photon characteristic energy, $h v=1486.6 \mathrm{eV}$ ). The $\mathrm{X}$-ray gun was operated at $300 \mathrm{~W}(15 \mathrm{kV}, 20 \mathrm{~mA})$. The work function of the spectrometer was adjusted using ultra-pure gold metal $\left(\mathrm{Au} 4 \mathrm{f}_{7 / 2}=84.0 \mathrm{eV}\right.$ ). The binding energy scale linearity was set to yield a difference of $848.6 \mathrm{eV}$ between the
$\mathrm{Cu} 2 \mathrm{p}_{3 / 2}$ and $\mathrm{Au} 4 \mathrm{f}_{7 / 2}$ photoelectron lines from ultrapure and sputtercleaned $\mathrm{Cu}$ and $\mathrm{Au}$ foils. The data were collected using a spherical capacitor analyzer (SCA) equipped with a seven-element "Omni-Focus V" lens. The angle between the analyzer and the X-ray source was $90^{\circ}$. The neutralizing electron gun was not used for analysis since no evidence of surface charging, or charge build-up was observed.

The XPS scans consisted of a survey scan, to identify all the species present, followed by high-resolution scans of the species of interest: oxygen (O $1 \mathrm{~s})$, carbon ( $\mathrm{C} 1 \mathrm{~s}$ ), iron ( $\mathrm{Fe} 2 \mathrm{p})$, chlorine $(\mathrm{Cl} 2 \mathrm{p})$, and sodium ( $\mathrm{Na}$ $1 \mathrm{~s})$. Survey scans were performed using an energy range of $1440 \mathrm{eV}$, analyzer pass energy of $187.85 \mathrm{eV}$, the step size of $1.6 \mathrm{eV}$. High-resolution scans were performed using an analyzer pass energy of $23.5 \mathrm{eV}$ with a step size of $0.1 \mathrm{eV}$. High-resolution analyses were calibrated to C $1 \mathrm{~s}$ (hydrocarbon) signal of $285.0 \mathrm{eV}$. The survey scans and high-resolution scans were performed at an emission angle $(\theta)$ of $5^{\circ}, 25^{\circ}, 45^{\circ}, 65^{\circ}$, and $85^{\circ}$ with respect to the surface normal. The higher the emission angle, the shallower the oxide film depth being analyzed, and hence all the XPS results would be presented in terms of passive oxide film depth.

\section{XPS data analysis}

The XPS data curve fitting and analysis were done using CasaXPS (V 2.3.16PR1.4) data processing software. The XPS data were semiquantitatively analyzed using the areas under curve fitted (deconvoluted) spectra, and sensitivity factors provided by CasaXPS's Scofield element library. High-resolution XPS spectra were curve fitted and deconvoluted to quantify the contribution of each chemical species (element associations) that comprise the spectra. Curve fitting required various constraints to be met simultaneously. ${ }^{15,16,72,73}$ Shirley background correction procedures and Gaussian (70\%)-Lorentzian (30\%) functions were used for curve fitting procedures of high-resolution spectra. All high-resolution XPS spectra envelopes were smoothed by SG Quadratic method with smoothing width parameter of $21 .^{73}$ All spectra were curve fitted to the minimum number of peaks required for an optimum fit and needed for corresponding chemical assignments using Casa-XPS data library (ver. 2.3.18). ${ }^{73}$ The detailed procedure for the curve fitting process is provided in other references. ${ }^{73,74}$

Accurate determination of the atomic structure of the oxide film could not be based on the variations of the sodium, chloride, carbon, and oxygen spectra since these elements are also present in the precipitates from the $\mathrm{NaOH}$ and $\mathrm{NaCl}$ solutions on the specimen surface. Despite the best cleaning practices, complete removal of precipitates is not ensured, as the harsh cleaning procedures might damage the oxide film. Since iron is not incorporated into the precipitates, only Fe $2 p$ XPS spectra were used in the analysis of the characteristics of oxide films.

The Fe $2 p$ XPS spectrum is composed of a doublet structure (2 peaks). The doublet structure is due to multiplets splitting (i.e., Fe $2 p_{3 / 2}$ and $\mathrm{Fe} 2 \mathrm{p}_{1 / 2}$ ). Based on the average of the binding energies reported for each compound in the literature, ${ }^{75,76}$ iron compounds of the passive film in this study can be classified into three groups as $\mathrm{Fe}$ metal, $\mathrm{Fe}^{+2}, \mathrm{Fe}^{+3}$. Furthermore, an additional component $\mathrm{Fe}^{+3}$ satellite was used in curve fitting analysis of $\mathrm{Fe}$ $2 p$, as suggested in other studies. ${ }^{16,75,77,78}$ Although it is possible to obtain much better curve fitting when additional peaks are used, their presence is improbable in the case of pure iron passivating in high $\mathrm{pH} \mathrm{NaOH}$ solution. The accurate identification of these peaks is quite challenging due to the proximity of peak positions; therefore, only the reported peaks were used in the analysis and the iron $2 p$ spectra were fitted to four iron components. The peak parameters of each component are presented in another reference. ${ }^{16}$

Assuming a uniform oxide film formation on the iron substrate, the film thickness was calculated from the oxide to metal intensity ratios at an emission angle of $5^{\circ}$ using the procedure described in Ghods et al. ${ }^{15}$

$\mathrm{d}_{\mathrm{ox}}=\lambda_{\mathrm{ox}}^{\mathrm{Fe}} \cos \theta \ln \left(1+\frac{\mathrm{l}_{\mathrm{ox}}^{\mathrm{Fe}}}{\mathrm{I}_{\mathrm{m}}^{\mathrm{Fe}}} \frac{N_{\mathrm{m}}^{\mathrm{Fe}}}{N_{\mathrm{ox}}^{\mathrm{Fe}}} \frac{\lambda_{\mathrm{ox}}^{\mathrm{Fe}}}{\lambda_{\mathrm{Fe}}}\right)$

where $d_{o x}(n m)$ is the thickness of iron oxide; $\mathrm{Fox}_{\mathrm{ox}}^{\mathrm{Fe}}$ and $\mathrm{I}_{\mathrm{m}}^{\mathrm{Fe}}$ are, the intensities of the total iron oxides and the metallic iron obtained from Fe $2 p$ spectra, respectively; $\mathrm{N}_{\mathrm{m}}^{\mathrm{Fe}}$ and $\mathrm{N}_{\mathrm{ox}}^{\mathrm{Fe}}$ are average atomic densities of iron oxides and metallic iron, respectively; and $\lambda_{\mathrm{ox}}^{\mathrm{Fe}}$ and $\lambda_{\mathrm{m}}^{\mathrm{Fe}}(\mathrm{nm})$ are attenuation lengths of iron oxide and metallic iron. ${ }^{79}$

\section{DATA AVAILABILITY}

The data that support the findings of this study are available from the corresponding author upon reasonable request. 


\section{ACKNOWLEDGEMENTS}

The study presented in this paper was fully funded by the National Science Foundation, CMMI, Grant No. 1435417. Part of this work used the Extreme Science and Engineering Discovery Environment (XSEDE) Comet at the San Diego Supercomputer Center (SDSC) and Stampede at the Texas Advanced Computing Center (TACC) at the University of Texas at Austin through allocation TG-ENG170002. XSEDE is supported by National Science Foundation grant number ACl-1053575. Part of this research was conducted at the Northwest Nanotechnology Infrastructure, a National Nanotechnology Coordinated Infrastructure site at Oregon State University, which is supported in part by the National Science Foundation (grant NNCl-1542101) and Oregon State University.

\section{AUTHOR CONTRIBUTIONS}

O.B.I. and L.Á. secured the funding, initiated, and supervised the project. O.B.I., L.Á, H.D. and Q.P. conceptualized and designed the modeling framework. H.D. performed the molecular dynamics simulations and analyzed the results with the support of Q.P., O.B.I., L.Á., H.D. and Q.P. interpreted the simulation data. O.B.I., L.Á. and P.M. conceptualized and designed the XPS and electrochemical experiments. P.M. performed the XPS and electrochemical experiments. O.B.I., L.Á., H.D., Q.P. and P.M. interpreted the experiments and compared their results with the modeling data. All the authors helped with paper writing and editing.

\section{ADDITIONAL INFORMATION}

Competing interests: The authors declare no competing interests.

Publisher's note: Springer Nature remains neutral with regard to jurisdictional claims in published maps and institutional affiliations.

\section{REFERENCES}

1. Jones, D. A. Principles and Prevention of Corrosion 2nd edn, 592 (Prentice Hall, Upper Saddle River, NJ, USA, 1996).

2. Revie, R. W. \& Uhlig, H. H. Corrosion and Corrosion Control 4th edn, 512 (WileyInterscience, Hoboken, NJ, USA, 2008).

3. Bertolini, L., Elsener, B., Pedeferri, P. \& Polder, R. Corrosion of Steel in Concrete: Prevention, Diagnosis, Repair 2nd edn, 434 (Wiley-VCH, Weinheim, Germany, 2000).

4. Hunkeler, F. Corrosion in reinforced concrete: processes and mechanisms. Bohni, H. (ed.), In Corrosion in Reinforced Concrete Structures. 1st edn, 264 (Woodhead Publishing, Cambridge, England, 2005).

5. Broomfield, J. P. Corrosion of Steel in Concrete 2nd edn, 296 (Taylor \& Francis, Abington, England, 2007).

6. Mehta, P. K. \& Monteiro, P. J. M. Concrete: Microstructure, Properties, and Materials 4th edn, 704 (McGraw-Hill Professional, New York, NY, USA, 2014).

7. Kurtis, K. E. \& Mehta, P. K. A critical review of deterioration of concrete due to corrosion of reinforcing steel. ACl Spec. Publ. 170, 535-554 (1997).

8. Koch, G. H. et al. Corrosion Cost and Preventative Strategies in the United States. Report No. FHWA-RD-01-156, 773 (NACE International, Houston, 2002).

9. Ghods, P., Isgor, O. B., McRae, G. \& Miller, T. The effect of concrete pore solution composition on the quality of passive oxide films on black steel reinforcement. Cem. Concr. Compos. 31, 2-11 (2009).

10. Li, L. \& Sagues, A. A. Chloride corrosion threshold of reinforcing steel in alkaline solutions - Cyclic polarization behavior. Corrosion 58, 305-316 (2002).

11. Hansson, C. M., Poursaee, A. \& Laurent, A. Macrocell and microcell corrosion of steel in ordinary Portland cement and high performance concretes. Cem. Concr. Res 36, 2098-2102 (2006).

12. Angst, U. M., Elsener, B., Larsen, C. K. \& Vennesland, O. Chloride induced reinforcement corrosion: electrochemical monitoring of initiation stage and chloride threshold values. Corros. Sci. 53, 1451-1464 (2011).

13. Alonso, C., Andrade, C., Castellote, M. \& Castro, P. Chloride threshold values to depassivate reinforcing bars embedded in a standardized OPC mortar. Cem. Concr. Res. 30, 1047-1055 (2000).

14. Ghods, P. et al. Nano-scale study of passive films and chloride-induced depassivation of carbon steel rebar in simulated concrete pore solutions using FIB/TEM. Cem. Concr. Res. 47, 55-68 (2013).

15. Ghods, P. et al. XPS depth profiling study on the passive oxide film of carbon steel in saturated calcium hydroxide solution and the effect of chloride on the film properties. Appl. Surf. Sci. 257, 4669-4677 (2011).

16. Ghods, P., Isgor, O. B., Bensebaa, F. \& Kingston, D. Angle-resolved XPS study of carbon steel passivity and chloride-induced depassivation in simulated concrete pore solution. Corros. Sci. 58, 159-167 (2012).
17. Sanchez-Moreno, M. et al. A theoretical approach of impedance spectroscopy during the passivation of steel in alkaline media. Electrochim. Acta 54, 7222-7226 (2009).

18. Sanchez, M. et al. Electrochemical impedance spectroscopy for studying passive layers on steel rebars immersed in alkaline solutions simulating concrete pores. Electrochim. Acta 52, 7634-7641 (2007).

19. Joiret, S. et al. Use of EIS, ring-disk electrode, EQCM and Raman spectroscopy to study the film of oxides formed on iron in $1 \mathrm{M} \mathrm{NaOH}$. Cem. Concr. Compos. 24, 7-15 (2002).

20. Gunay, H. B. et al. Characterization of atomic structure of oxide films on carbon steel in simulated concrete pore solutions using EELS. Appl. Surf. Sci. 274, 195-202 (2013).

21. Heine, M. A., Keir, D. S. \& Pryor, M. J. Specific effects of chloride and sulfate ions on oxide covered aluminum. J. Electrochem. Soc. 112, 24-32 (1965).

22. Richardson, J. A. \& Wood, G. C. A study of the pitting corrosion of Al byscanning electron microscopy. Corros. Sci. 10, 313-323 (1970).

23. Hashimoto, K. \& Asami, K. X-Ray photoelectron spectroscopic study of the passivity of ferritic 19cr stainless-steels in 1-Nhcl. Corros. Sci. 19, 251-260 (1979).

24. Lin, L., Chao, C. \& Macdonald, D. A point defect model for anodic passive films II. Chemical breakdown and pit initiation. J. Electrochem. Soc. 128, 1194-1198 (1981).

25. Macdonald, D. D. The point-defect model for the passive state. J. Electrochem. Soc. 139, 3434-3449 (1992).

26. Ghods, P., Isgor, O., McRae, G. \& Gu, G. Electrochemical investigation of chlorideinduced depassivation of black steel rebar under simulated service conditions. Corros. Sci. 52, 1649-1659 (2010).

27. Angst, U., Elsener, B., Larsen, C. K. \& Vennesland, O. Critical chloride content in reinforced concrete - a review. Cem. Concr. Res. 39, 1122-1138 (2009).

28. Goni, S. \& Andrade, C. Synthetic concrete pore solution chemistry and rebar corrosion rate in the presence of chlorides. Cem. Concr. Res. 20, 525-539 (1990).

29. Andrade, C. \& Page, C. L. Pore solution chemistry and corrosion in hydrated cement systems containing chloride salts - a study of cation specific effects. $B r$. Corros. J. 21, 49-53 (1986).

30. Gunay, H. B., Isgor, O. B. \& Ghods, P. Kinetics of passivation and chloride-induced depassivation of iron in simulated concrete pore solutions using electrochemical quartz crystal nanobalance. Corrosion 71, 615-627 (2015).

31. Ogura, K. \& Kaneko, M. The Pit initiation mechanism on passive iron under both open-circuit and controlled potential conditions. Corros. Sci. 23, 1229-1238 (1983).

32. Zakroczymski, T., Fan, C. J. \& Szklarskasmialowska, Z. Passive film formation on iron and film breakdown in a sodium-hydroxide solution containing chlorideions. J. Electrochem. Soc. 132, 2868-2871 (1985).

33. van Duin, A. C. T. et al. Development and validation of a ReaxFF reactive force field for $\mathrm{Cu}$ cation/water interactions and copper metal/metal oxide/metal hydroxide condensed phases. J. Phys. Chem. A 114, 9507-9514 (2010).

34. Aryanpour, M., van Duin, A. C. T. \& Kubicki, J. D. Development of a reactive force field for iron-oxyhydroxide systems. J. Phys. Chem. A 114, 6298-6308 (2010).

35. Raymand, D. et al. Water adsorption on stepped ZnO surfaces from MD simulation. Surf. Sci. 604, 741-753 (2010).

36. Russo, M. F., Li, J. R., Mench, M. \& van Duin, A. C. T. Molecular dynamic simulation of aluminumewater reactions using the ReaxFF reactive force field. Int. J. Hydrog. Energ. 36, 5828-5836 (2011).

37. Jeon, B., Sankaranarayanan, S. K. R. S., van Duin, A. C. T. \& Ramanathan, S. Atomistic insights into aqueous corrosion of copper. J. Chem. Phys. 134, 234706-234716 (2011).

38. Jeon, B., Sankaranarayanan, S. K. R. S., van Duin, A. C. T. \& Ramanathan, S. Reactive molecular dynamics study of chloride ion interaction with copper oxide surfaces in aqueous media. ASC Appl. Mater. Interfaces 4, 1225-1233 (2012).

39. Assowe, O. et al. Reactive molecular dynamics of the initial oxidation stages of $\mathrm{Ni}$ (111) in pure water: effect of an applied electric field. J. Phys. Chem. A 116, 11796-11805 (2012).

40. Verners, O. \& van Duin, A. C. T. Comparative molecular dynamics study of fcc-Ni nanoplate stress corrosion in water. Surf. Sci. 633, 94-102 (2015).

41. Zou, C. et al. Molecular dynamics simulations of the effects of vacancies on nickel self-diffusion, oxygen diffusion and oxidation initiation in nickel, using the ReaxFF reactive force field. Acta Mater. 83, 102-113 (2015).

42. Senftle, T. P. et al. The ReaxFF reactive force-field: development, applications and future directions. npj Comput. Mater. 2, 15011 (2016).

43. Otte, K., Schmahl, W. W. \& Pentcheva, R. Density functional theory study of water adsorption on FeOOH surfaces. Surf. Sci. 606, 1623-1633 (2012).

44. Nguyen, M. T., Seriani, N. \& Gebauer, R. Water adsorption and dissociation on alpha-Fe2O3(0001): $\mathrm{PBE}+\mathrm{U}$ calculations. J. Chem. Phys. 138, 194709194701-194708 (2013).

45. Pang, Q., DorMohammadi, H., Isgor, O. B. \& Árnadóttir, L. Density functional theory study on the effect of $\mathrm{OH}$ and $\mathrm{Cl}$ adsorption on the surface structure of aFe2O3. Comput Theor. Chem. 1100, 91-102 (2017). 
46. Yin, S., Ma, X. \& Ellis, D. E. Initial stages of $\mathrm{H}_{2} \mathrm{O}$ adsorption and hydroxylation of $\mathrm{Fe}-$

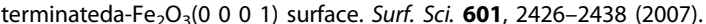

47. Soon, A., RTodorova, M., Delley, B. \& Stampfl, C. Oxygen adsorption and stability ofsurface oxides on $\mathrm{Cu}(111)$ : a first-principles investigation. Phys. Rev. $B$ - Condens. Matter Mater. Phys. 73, 1-13 (2006).

48. Zhang, C. H., Liu, M., Jin, Y. \& Sun, D. B. The corrosive influence of chloride ionspreference adsorption ona- $\mathrm{Al}_{2} \mathrm{O}_{3}(0001)$ surface. Appl. Surf. Sci. 347, 386-392 (2015).

49. Poursaee, A. \& Hansson, C. M. Reinforcing steel passivation in mortar and ore solution. Cem. Concr. Res. 37, 1127-1134 (2007).

50. DorMohammadi, H., Pang, Q., Isgor, O. B. \& Árnadóttir, L. Atomistic simulation of initial stages of iron corrosion in pure water using reactive molecular dynamics. Comp. Mater. Sci. 145, 126-132 (2018).

51. Dwyer, D. J., Kelemen, S. R. \& Kaldor, A. The water dissociation reaction on clean and oxidized iron (110). J. Chem. Phys. 76, 1832-1838 (1982).

52. Dwyer, D. J. \& Simmons, G. W. A study of the initial reaction of water vapor with Fe(001) surface. Surf. Sci. 64, 617-633 (1977).

53. Hung, S., Schwartz, W. H. \& Bernasek, J. Sequential oxidation of Fe (100) by water adsorption: formation of an ordered hydroxylated surface. Surf. Sci. 248, 332-343 (1991).

54. Eder, M., Terakura, K. \& Hafner, J. Initial stages of oxidation of (100) and (110) surfaces of iron caused by water. Phys. Rev. B. 64, 115426-115433 (2001).

55. Liu, S. et al. Coverage dependent water dissociative adsorption on the clean and O-precovered Fe(111) surfaces. J. Phys. Chem. C. 119, 11714-11725 (2015).

56. Stern, O. The theory of the electrolytic double layer. Z. Elektrochem. Angew. Phys. Chem. 30, 508-517 (1924)

57. Gamburg, Y. D. \& Zangari, G. The structure of the metal-solution interface. In: Gamburg, Y.D. \& Zangari, G. (ed.), Theory and Practice of Metal Electrodeposition 27-51 (Springer, New York, NY, USA, 2011).

58. Jeon, B., van Overmeere, Q., van Duin, A. C. T. \& Ramanathan, S. Nanoscale oxidation and complex oxide growth on single crystal iron surfaces and external electric field effects. PCCP 15, 1821-1831 (2013).

59. Goel, A. Colloidal Chemistry. 254 (Discovery Publishing House, New Delhi, India, 2006).

60. Plimpton, S. Fast parallel algorithms for short-range molecular dynamics. J. Comput. Phys. 117, 1-19 (1995).

61. Towns, J. et al. XSEDE: accelerating scientific discovery. Comput. Sci. Eng. 16 62-75 (2014)

62. van Duin, A. C. T., Dasgupta, S., Lorant, F. \& Goddard, W. A. ReaxFF: a reactive force field for hydrocarbons. J. Phys. Chem. A 105, 9396-9410 (2001).

63. van Duin, A. C. T. et al. ReaxFF SiO reactive force field for silicon and silicon oxide systems. J. Phys. Chem. A 107, 3803-3812 (2003).

64. Psofogiannakis, G. M., McCleerey, J. F., Jaramillo, E. \& van Duin, A. C. T. ReaxFF reactive molecular dynamics simulation of the hydration of Cu-SSZ-13 zeolite and the formation of Cu dimers. J. Phys. Chem. C. 119, 6678-6687 (2015).

65. Rahaman, O. et al. Development of a ReaxFF reactive force field for aqueous chloride and copper chloride. J. Phys. Chem. A 114, 3556-3569 (2010).
66. Nose, S. A molecular dynamics method for simulations in the canonical ensemble. Mol. Phys. 52, 255-269 (1984).

67. Hoover, W. G. Canonical dynamics: equilibrium phase-space distributions. Phys. Rev. A. 31, 1695-1698 (1985)

68. Allen, M. P. \& Tildesley, D. J. Computer Simulation of Liquids. 1st edn, 385 (Clarendon Press, Oxford, England, 1987).

69. Dunbar, R. C. Deriving the Maxwell distribution. J. Chem. Educ. 59, 22-24 (1982)

70. Peckham, G. D. \& McNaught, I. J. Applications of Maxwell-Boltzmann distribution diagrams. J. Chem. Educ. 69, 554-559 (1992).

71. Rajagopalan, K. S. \& Dey, N. C. Stern-Geary method of measurement of corrosion rate. J. Sci. Ind. Res. India 35, 35-40 (1976).

72. Ghods, P. Multi-Scale Investigation of the Formation and Breakdown of Passive Films on Carbon Steel Rebar in Concrete. Ph.D. thesis, 300, Carleton Univ. Devon, England. (2010).

73. Fairely, N. Introduction to XPS and AES. CasaXPS Manual 2.3.15. 177 (Casa Software Ltd., Devon, England, 2009).

74. van der Heide, P. X-Ray Photoelectron Spectroscopy: An Introduction to Principles and Practices. 364 (Wiley, Hoboken, NJ, USA, 2011).

75. Wanger, C. D. et al. Handbook of X-ray Photoelectron Spectroscopy. 190 (PerkinElmer Corp., Physical Electronics Division, Eden Prairie, MN, USA, 1979).

76. Moulder, J. F., Chastain, J. \& King, R. C. Handbook of X-ray Photoelectron Spectroscopy: A Reference Book of Standard Spectra for Identification and Interpretation of XPS Data. 261 (Physical Electronics, Eden Prairie, MN, USA, 1995).

77. Grosvenor, A. P., Kobe, B. A., Biesinger, M. C. \& Mclntyre, N. S. Investigation of multiplet splitting of Fe $2 p$ XPS spectra and bonding in iron compounds. Surf. Interface Anal. 36, 1564-1574 (2004).

78. Fujii, T. et al. In situ XPS analysis of various iron oxide films grown by $\mathrm{NO}_{2}$-assisted molecular-beam epitaxy. Phys. Rev. B 59, 3195-3202 (1999).

79. Seah, M. P. \& Dench, W. A. Quantitative electron spectroscopy of surfaces: a standard data base for electron inelastic mean free paths in solids. Surf. Interface Anal. 1, 2-11 (1979).

(i) Open Access This article is licensed under a Creative Commons Attribution 4.0 International License, which permits use, sharing, adaptation, distribution and reproduction in any medium or format, as long as you give appropriate credit to the original author(s) and the source, provide a link to the Creative Commons license, and indicate if changes were made. The images or other third party material in this article are included in the article's Creative Commons license, unless indicated otherwise in a credit line to the material. If material is not included in the article's Creative Commons license and your intended use is not permitted by statutory regulation or exceeds the permitted use, you will need to obtain permission directly from the copyright holder. To view a copy of this license, visit http://creativecommons. org/licenses/by/4.0/.

(c) The Author(s) 2019 